\title{
Educación y devoción en el MS 551 de Besançon, Les Miracles de Nostre Dame de Gautier de Coinci*
}

\author{
Fuensanta MurCia NicOLÁs \\ Universidad de Murcia \\ Departamento de Historia del Arte \\ fmn2@um.es
}

\section{RESUMEN}

En el presente artículo se pretende abordar el estudio de los márgenes del manuscrito 551 de Besançon que recoge la obra de Gautier de Coinci, Les Miracles de Nostre Dame. Fuera del relato de los milagros, se puede encontrar en los motivos de la marginalia y glosas latinas un discurso donde se une la devoción con la educación: escenas de la vida profana como la caza y torneos de justa, bestiarios que hablan de la humildad, penitencia y castidad, apoyados por pequeñas sentencias tomadas principalmente de las Sagradas Escrituras y Padres de la Iglesia. Un repertorio de textos e imágenes que apuntan a un propietario laico, sin descartar que fuera una mujer, debido a que dichas virtudes eran las más importantes dentro de los programas de conducta femeninos de la Francia del siglo XIII.

Palabras clave: marginalia; glosas; manuscritos; Gautier de Coinci.

\section{Education and Devotion in Besançon Manuscript 551, Les Miracles de Nostre Dame by Gautier de Coinci}

\begin{abstract}
This article is an attempt to study the margins in the Besançon Codex, which contains Les Miracles de Nostre Dame by Gautier de Coinci. Outside of the writing miracles, we can find in the decorative margins and the Latin annotations one speech where devotion and education are connected: scenes of secular life like the hunting and jousting, bestiary that talk about humility, penitence and chastity, and different advices extracted from the Holy Scriptures and the Fathers of the Church. This catalogue can point to a secular owner, perhaps a young woman, as these virtues were the most important ones in the educational females programs in France during the 13th century.
\end{abstract}

Key words: marginalia; side annotations; manuscripts; Gautier de Coinci.

\footnotetext{
* Este artículo se enmarca dentro del proyecto HAR2012 34154 del MICINN, gracias a una beca FPU del Ministerio de Educación, Cultura y Deporte.
} 
La obra de Gautier de Coinci (1178-1236), Les Miracles de Nostre Dame ${ }^{1}$, es una de las colecciones de milagros marianos más importantes del siglo XIII junto con las Cantigas de Santa María de Alfonso X el Sabio ${ }^{2}$. Ambas no solo cumplían una función didáctica - moral, sino que también tenían un papel importante dentro de la devoción privada ${ }^{3}$. Esto se refleja en las innovaciones que fueron introducidas por dichos autores, que iban destinadas a mostrar tanto su fervor personal como la exaltación de la Virgen y su poder de mediación. La colección de Gautier tuvo una especial acogida debido al importante número de manuscritos conservados entre los siglos XIII y XIV, de los cuales se conservan varios ejemplares iluminados ${ }^{4}$. Acerca de su biografía, son Arlette Ducrot - Granderye y Frédéric Koenig los que más datos aportan, aunque este hecho se ve favorecido porque la comunidad a la que perteneció el monje benedictino era bastante importante y, además, él mismo cita algunos pasajes de su vida en la propia obra. Originario del pueblo Coincy-l'Abbaye, su linaje familiar no sería del todo humilde puesto que un tío suyo ostentaba un cargo eclesiástico ${ }^{5}$. Ingresa con dieciséis años en el monasterio de Saint Médard de Soissons, donde inicia sus estudios, e incluso viajaría a París para completar la formación teológica. Más tarde, fue ordenado prior de Vic-sur-Aisne, donde comienza a escribir sus

\footnotetext{
1 GAUTIER DE COINCI, Les Miracles de Nostre Dame, ed. Frédéric V. KOENIG, vol. 4, Genève, Droz, 1966.

2 ALFONSO X El SABIO, Las Cantigas de Santa Maria, ed. Walter METTMANN, Madrid, Castalia, 1986.

3 La bibliografía sobre la relación entre el culto a la Virgen y la literatura devocional es muy amplia, aquí se citan las obras más importantes: AHSMANN, Hurbertus P. J. M., Le Culte de la Vierge et la Littérature Français Profane du Moyen Âge, Paris, A. Picard, 1930; ARCANGELI, Maria Laura, Aspetti del tema della Vergine nella literatura francese del Medioevo, Venezia, Instituto Universitario Collana Ca' Foscari, 1968; AXELSEN, Angelica, Supernatural Beings in the French Medieval Dramas, with especial reference to the Miracles of The Virgin, Copenague, Levin \& Munksgaard, 1923; BARNAY, Sylvie, El Cielo en la Tierra. Las Apariciones de la Virgen en la Edad Media, Madrid, Encuentro, 1999; BAYO, Juan Carlos, "Las colecciones universales de milagros de la Virgen hasta Gonzalo de Berceo", en Bulletin of Spanish Studies, vol. LXXXI, $\mathrm{n}^{\circ}$ 7-8, 2004, pp. 849-871; DURHAM, Michael S., Miracles of Mary: Apparitions, Legends and Miraculous Works of Blessed Mary, New York, Blackberry Press, 1995; EDGREN, Helen, Mercy and Justice: Miracles of The Virgin in Finnish Medieval Wall-Paintings, Helsinki, 1993; FLORY, David A., Marian representation in the Miracles tales of thirteenth-century Spain and France, Washington D. C, The Catholic University of America Press, 2000; MONTOYA MARTÍNEZ, Jesús, Las Colecciones de Milagros de la Virgen en la Edad Media, Granada, Servicio de Publicaciones de la Universidad de Granada, 1981; O'SULLIVAN, Daniel E., Maria Devotion in the thirteenth century french lyric, Toronto, University of Toronto Press, 2005; REED, Teresa P., Shadows of Mary: redding the Virgin Mary in medieval texts, Cardiff, University of Wales Press, 2003; WARD, Benedicta, Miracles and the medieval mind: Theory, record and event, 1000-1215, Filadelfia, University of Pennsylvania Press, 1982; YARZA LUACES, Joaquín, "Historias milagrosas de la Virgen en el arte del siglo XIII", en Lambard: Estudis d'Art Medieval, no 15, 2002-2003, pp. 205-246.

4 Se contabilizan cerca de treinta ejemplares, catalogados por Arlette Ducrot-Grandeyre, en la década de 1930: DUCROT-GRANDEYRE, Arlette, Études sur Les Miracles de Nostre Dame de Gautier de Coinci, Helsinki, Société de Littérature Finnoise, 1932 (reimpreso en Ginebra, 1980). Posteriormente, este estudio ha sido revisado en RUSSAKOFF, Anna, Imaging the Miraculous. Les Miracles de Nostre Dame, Paris, BnF, n.acq. fr. 24541, Tesis Doctoral, New York University, 2006; STONES, Alison y KRAUSE, Kathy (eds.), Gautier de Coinci. Miracles, Music and Manuscripts, Turnhout, Brepols, 2007; STONES, Alison, Gothic Manuscripts c. 1260 - 1320, vol. 1, Turnhout, Brepols, 2013.

5 GAUTIER DE COINCI (1966), op. cit., vol. I, p. XX; BEAUSSART, François-Jérôme: "L'auteur et son projet dans la littérature mariale narrative aux XIIe et XIIIe siècles", en BUSCHINGER, Daniel (ed.), L'effet auteur au Moyen Âge, Amiens, Université de Picardie-Jules Verne, 2003, pp. 1-11.
} 
milagros en torno al año 1218 y que, seguramente, acabó diez años después, sobre el $1227^{6}$. El corpus de milagros pudo ser extraído de diferente fuentes, tanto DucrotGranderye como Koenig coinciden en que estas pertenecerían a la biblioteca de la comunidad de Soissons, especialmente el texto latino de Huges Persit que actualmente se conserva en la Biblioteca Nacional de Francia ${ }^{7}$. Lo determinante de Gautier no es la recopilación, sino las novedades que incluye en el tratamiento del texto, con especial atención en los fragmentos líricos. La composición de la obra se resume en dos libros de estructura más o menos simétrica; cada uno consta de un prólogo, siete canciones, la narración de los milagros, finalizando con composiciones líricas que varían desde oraciones, poemas moralizantes y saludos ${ }^{8}$. En ambos tomos, el autor emplea un lenguaje nuevo, en el cual une la retórica con los términos y supuestos del amor cortés, dando un giro literario diferente, ensalzando la figura de la Virgen a través del hecho milagroso ${ }^{9}$. Su intención final era convertir la colección en un texto de devoción dentro del culto mariano que eclosionaba en esos momentos, más allá de una recopilación estrictamente hagiográfica.

\section{El Manuscrito 551 de Besançon: estado de la cuestión}

Acerca del corpus de manuscritos conservados, el catálogo elaborado por DucrotGranderye en 1932, el apartado dedicado por Koenig en su edición crítica del texto de Gautier, la tesis doctoral de Russakoff, y el volumen dirigido por Stones y Krause ${ }^{10}$ diferencian dos grupos, aquellos denominados ejemplares completos o que poseen el cuerpo íntegro de la obra, y los incompletos, que poseen solo fragmentos sueltos $\mathrm{o}$ insertados en otro tipo de composición lírica o narrativa ${ }^{11}$. Al primero pertenece el manuscrito 551 conservado en la Biblioteca de Besançon, compuesto por 180 folios de 345 x $245 \mathrm{~mm}$. Fue realizado en torno a las décadas de 1260 - 1270 en la zona sur de Francia. Posee 183 ilustraciones, y motivos marginales en los 30 primeros folios. Perteneció a Philippe de Hochberg, François - Charles de Sonnet, y Jean Batiste

6 DUCROT-GRANDEYRE, Arlette (1932), op. cit., pp. 159 y ss.; OKUBO, Masami: "La formation de la colecction des Miracles de Gautier de Coinci”, en Romania, n⿳ 123, 2005, pp. 141-212 y 406-458.

7 DUCROT-GRANDEYRE, Arlette (1932), op. cit., pp. 13-14; KOENIG, Frédéric V. (1966), op.cit., pp. XXXI-XXXIII; WILSON, Evelyn F., The Stella Maris of John of Garland, Cambridge, The Medieval Academy of America, 1946, pp. 31-32.

8 El primer libro tiene la siguiente estructura: prólogo, canciones (7), milagros (35), y oraciones a Santa Leocadia (4), y la de segundo: prólogo, canciones (7), milagros (23), poemas moralizantes (2), saludos y oraciones (4): GAUTIER DE COINCI (1966), op. cit., p. VIII.

9 BOLDUC, Michelle, "The Poetics of Authorship and Vernacular Religious Devotion", en KARANTNUNN, Susan C. (ed.), Varieties of Devotion in the Middle Ages and Renaissance, Turnhout, Brepols, 2003, pp. 125-143; MONTOYA MARTÍNEZ, Jesús, "Los prólogos de Gautier de Coinci”, en Estudios del Románico, $\mathrm{n}^{\circ}$ 2, 1979-1980, pp. 9-7; SWITTEN, Margaret, "Borrowing, citation, and authorship in Gautier de Coinci's Miracles de Nostre Dame", en GREEN, Virginie (ed.), The Medieval Author in Medieval French Literature, New York, Palgrave, 2007, pp. 29-59.

10 DUCROT-GRANDERYE, Arlette (1932), op. cit., pp. 16-18; RUSSAKOFF, Anna (2006), op. cit., pp. 76-95; STONES, Alison y KRAUSE, Kathy (2007), op. cit., pp. 345-347.

11 DUCROT-GRANDERYE, Arlette (1932), op. cit., pp. 168-169. 
Boisot, antes de llegar a su actual emplazamiento a finales del siglo XVIII ${ }^{12}$. Su datación, especialmente dificultosa, ha sido revisada en varias ocasiones. Si bien Ducrot - Granderye lo fecha a principios del siglo XIV, su estudio es de carácter filológico, y deja de lado los aspectos codicológicos e iconográficos ${ }^{13}$. En la obra colectiva dirigida por Jacques Dalarun, Le Moyen Âge en Lumière, aparece catalogado en la segunda mitad del siglo XIII al este de Francia ${ }^{14}$, cronología que retoma Anna Russakoff en su tesis doctoral, aunque la acota a finales de dicha centuria ${ }^{15}$. La datación más precisa es la que da Alison Stones, entre 1260 y 1270 en la zona sur ${ }^{16}$, basándose en el análisis de las ilustraciones y la grafía, estableciendo similitudes con otros ejemplares de esas mismas fechas ${ }^{17}$. Finalmente, otra vez Stones en su estudio recientemente publicado sobre los manuscritos góticos franceses, retoma esta hipótesis señalando la zona de Narbona como posible lugar de origen ${ }^{18}$.

El códice de Besançon presenta todo el texto de la obra de Gautier, escrita a dos columnas por página pero la iluminación está incompleta ${ }^{19}$. Aun así, posee una variada gama de recursos decorativos, entre los que se incluyen varios tipos de imágenes que acompañan a la colección. En primer lugar, todos los diseños de página están delimitados por un marco, que rodea la caja de justificación y marca el intercolumnio $^{20}$. Se compone de tres líneas verticales, siguiendo las líneas maestras, rematadas en los extremos con volutas. Los colores empleados son el azul y rojo, además de lámina de oro. Otro tipo son las iniciales decoradas presentes en casi todos los cuadernos del manuscrito, decoradas con motivos vegetales y situadas siempre al comienzo del párrafo. También, en los primeros folios del manuscrito, hay iniciales historiadas de medidas similares a la columna de texto. Pero el tipo más frecuente, son las ilustraciones insertadas en el relato. Las podemos encontrar de forma rectangular y circular, mientras las primeras se colocan en cualquier parte de la columna,

12 MARSOT, Adeline, Étude d'un manuscrit: 'Les Miracles de Notre Dame' de Gautier de Coinci, Université de Franco Comte, Besançon, 1989; MURCIA NICOLÁS, Fuensanta, 'Les Miracles de Nostre Dame’ de Gautier de Coinci. Estudio codicológico del ms. 551 de la Biblioteca de Besançon, Universidad de Murcia, 2010.

13 DUCROT-GRANDERYE, Arlette (1932), op. cit., pp. 51-54.

14 DALARUM, Jacques (dir.), Le Moyen Âge en Lumière: Manuscrits Enluminés des Bibiothèques de France, Paris, Fayard, 2002, p. 393.

15 RUSSAKOFF, Anna (2006), op. cit., pp. 305- 308 (Appendix 5. Short Catalogue of Complete Gautier de Coinci MND Manuscripts).

16 STONES, Alison y KRAUSE, Kathy (2006), op. cit., p. 337 (Appendix IV. Illustrated Miracles de Nostre Dame Manuscripts).

17 Ibid., p. 95 (Notes on the artistic context of some Gautier de Coinci manuscripts).

18 STONES, Alison, Gothic Manuscripts c. 1260 - 1320, vol. 1, Turnhout, Brepols, 2013, p. 75.

19 Sobre los aspectos codicológicos: MURCIA NICOLAS, Fuensanta, "Les Miracles de Nostre Dame de Gautier de Coinci. El MS 551 de la Biblioteca Municipal de Besançon”, en Miscelánea Medieval Murciana, vol. XXXVI, 2012, pp. 115-129.

20 Para los términos referentes a los aspectos codicológicos, vid. OSTOS SALCEDO, Pilar et al., Vocabulario de Codicología, Madrid, Arcos Libros, 1997 (traducción y revisión de MUZERELLE, Denis, Vocabulaire Codicologique : répertoire méthodologique des termes français aux manuscrits, Paris, CEMI, 1985, disponible on-line http://vocabulaire.irht.cnrs.fr/pages/vocab2.htm); RUÍZ GARCÍA, Elisa, Manual de Codicología, Madrid, Fundación Germán Sánchez Ruipérez, Editorial Salamanca, 1988, además de la obra imprescindible de WEITZMANN, Kurt, El rollo y el códice. Un estudio del origen y el método de iluminación de textos, Madrid, Nerea, 1990 (1947). 
las segundas se disponen siempre en la parte inferior de la página. Por último, hay que hacer una mención especial al contenido de sus márgenes, tanto por el repertorio de imágenes como por la presencia de anotaciones en latín ${ }^{21}$. Es en dicho espacio, fuera del discurso principal de la obra, donde podemos descifrar algunas claves sobre el encargo y el destinatario del manuscrito. La ausencia de datos anteriores al siglo $\mathrm{XV}$; momento en el que está documentado el primer dueño, Phillipe de Hochberg ${ }^{22}$, hacen de este ejemplar uno de los más controvertidos de la historiografía actual. En el presente artículo se pretende abordar el estudio de ambos aspectos, la marginalia y las glosas, para poder esclarecer el posible propietario o lector. Dichas imágenes nos muestran actividades de la vida laica y profana, especialmente aquellas ligadas a la aristocracia, como la caza y los torneos de justa, mientras que las citas son un repertorio de consejos morales, incluidos en los modelos educativos propuestos por los mendicantes a lo largo del siglo XIII. Ambos discursos señalan hacia un encargo hecho para una persona muy joven, la cual podría encontrar en este códice tanto el uso devocional como el educacional.

\section{El repertorio de la marginalia y las imágenes de la vida profana}

Como parte de la tarea inconclusa de la ilustración del códice se disponen, en los treinta primeros folios, varias imágenes fuera de la caja de escritura. Estos motivos, denominados marginalia, suponen hoy en día un punto importante de discusión dentro del estudio de los manuscritos medievales ${ }^{23}$. Más allá de este debate, el punto de interés en este caso es cómo ese repertorio nos puede indicar el tipo de propietario, bien laico o bien eclesiástico. Una parte importante corresponde a la representación de diferentes animales ${ }^{24}$, entre los que destacan el águila, el león, el ciervo y la cigüeña. El águila aparece en seis ocasiones, cazando, sola y con sus crías. Además

21 El manuscrito de Besançon no es el único que presenta esta característica. Los ejemplares $\mathrm{N}$ (BnF, fr. 25532), S (BnF, n. acq. fr. 24541) y E (BnF, fr. 817) también poseen glosas en su márgenes. Sin embargo, estos tres ejemplares son más similares tanto en el contenido como localización de las mismas. Veikko Väanamen, en su estudio sobre estas anotaciones, señala que los MS N y S son prácticamente iguales, debido a que ambos están localizados en el área de Soissons, vid. VÄANAMEN, Veiko, Gloses Marginales des Miracles de Gautier de Coinci, Helsinki, Annales Academiae Scientiorum Fennicae, 1945.

22 Sobre la familia Hochberg y, especialmente, su biblioteca: PIAGET, Arthur, Pages d'Historie Neuchâteloise, Neuchâtel, Société d'Histoire et Archéologie, 1935, pp. 143-168.

23 Sin duda uno de los estudios más innovadores, al mismo tiempo que polémico, es el de CAMILLE, Michael, Image on the Edge. The Margins of Medieval Art, London, Reaktion Books, 1992. Otros trabajos importantes son el estudio recopilatorio de RANDALL, Lilian M. C, Images in the Margins of Gothic Manuscripts, Los Angeles, California University Press, 1966, y, más recientes, MOORE HUNT, Elizabeth, Illuminating the Borders of Nothern French and Flemish Manuscripts, New York, Routledge, 2007; WIRTH, Jean, Les Marges à Drôleries des Manuscripts Gothiques, Ginebra, Droz, 2008.

24 Vid. BALPE, Jean-Pierre, Le Bestiaire Fantastique, Paris, Larousse, 1976; CARMODY, Francis J., "Le Diable des Bestiaires", en Cahiers de l'Association Internationale des Études Françaises, vol. 3-5, 1953, pp. 79-85; CHARBONNEAU- LASSAY, Louis, Le Bestiaire du Christ, Milano, Arche, 1971; KAPPLER, Claude, Monstres, démons et merveilles à la fin du Moyen Âge, Paris, Payot, 1980; KLINGENDER, Francis, Animals in the Art and Thought to the End of the Middle Ages, London, Poutledge and Kegan Paul, 1971; WOODRUFF, Helen, "The Physiologus of Bern", en The Art Bulletin, vol. XII, 1930, pp. 226- 253. 
de estar relacionada con las clases del poder, su interpretación también habla de la purificación del alma y la penitencia ${ }^{25}$. En el margen inferior del folio 11v (fig. 1), aparecen dos águilas en sus nidos ${ }^{26}$, lo que puede hacer referencia al fragmento del Bestiario Toscano:

"Y tiene dos características: una es que ella prueba a sus hijos, si pueden mirar firmemente al sol. Si ella comprueba que miran con firmeza, está segura entonces que son sus hijos. Aquellos que son verdaderos hijos, son los que miran con los ojos del corazón hacia Cristo" 27.

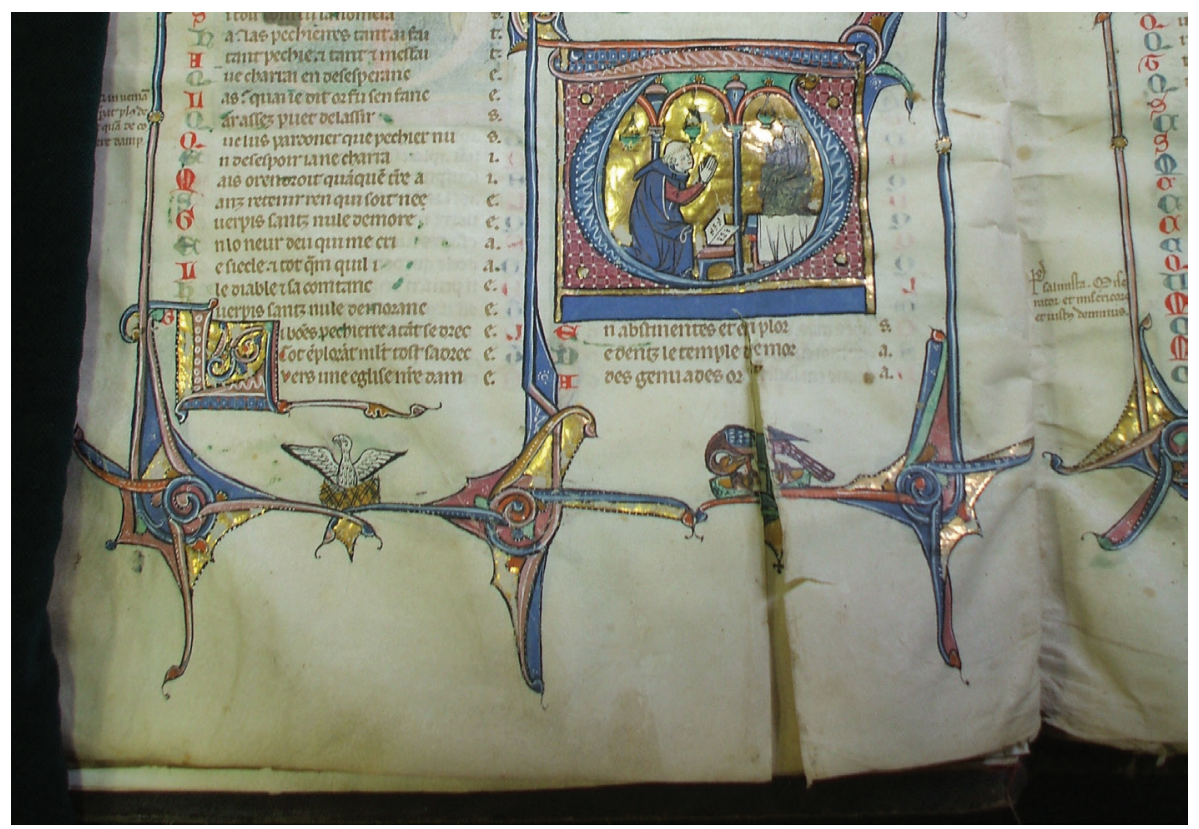

Fig. 1. Águilas en sus nidos. Besançon, MS 551, f. 11, margen inferior.

El segundo más representado es el león, rey de las bestias y figura del Cristo victorioso. Cuando aparece sobre sus crías, como en el margen superior del f. 3v. (fig. 2), es una analogía de la Resurrección y el perdón de los pecados: "La leona da a luz al cachorro como muerto y ciego, tendiéndose a su lado, durante tres días, fijos los ojos en él. Transcurrido este tiempo, se aproxima el león al cachorro y echa su aliento sobre él, que recupera la vida y abre los ojos" ${ }^{28}$. Otro animal cristológico es el ciervo ${ }^{29}$,

25 SEBASTIÁN LÓPEZ, Santiago, El Fisiólogo atribuido a San Epifanio, seguido del Bestiario Toscano, Madrid, Ediciones Tuero, 1986, pp. 39- 47; MALAXECHEVERRÍA, Ignacio, Bestiario Medieval, Madrid, Siruela, 2002, pp. 133-138.

26 RANDALL, Lilian M. C. (1966), op. cit., p. 95.

27 SEBASTIÁN LÓPEZ, Santiago (1986), op. cit., p. 45

28 Ibid., pp. 14-15; MALAXECHEVERRÍA, Ignacio (2008), op. cit., p. 94

29 RANDALL, Lilian M. C. (1966), op. cit., pp. 216-217. 


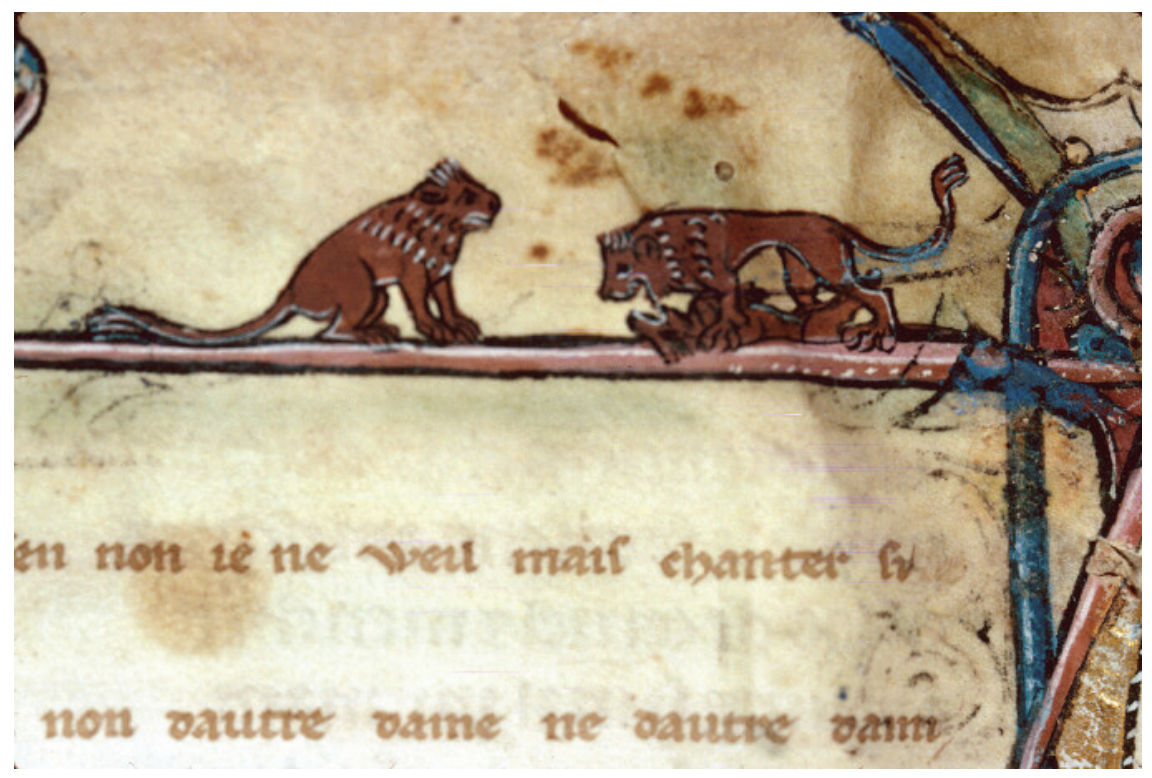

Fig. 2. León con su crías. Besançon, MS 551, f. 3v, margen superior.

que aparece tanto en forma de macho como de hembra, y que nos habla del bautismo y de la penitencia, sobre todo si se muestra enfrentado con la serpiente ${ }^{30}$. Por último, quedaría la cigüeña ${ }^{31}$ que representa la castidad:

"La cigüeña es una ave enteramente casta. El macho ni provoca a la hembra con sus caricias para llegar al coito, ni la violenta. Además la misma ave alimenta, con ejemplar piedad, a sus progenitores en la vejez. Así debemos cumplir aquellos divinos preceptos: alejarnos del mal y hacer el bien, honrar a tu padre y a tu madre, además, no fornicarás" ${ }^{32}$.

En los márgenes superiores de ambas caras del folio 13 aparece enfrentada con el búho (fig. 3), símbolo del hombre entregado al vicio: "El búho representa a los pecadores que se entregan a las tinieblas y huyen de la luz de la justicia" ${ }^{33}$. Si bien es cierto que no todos los bestiarios incitan a una interpretación alegórica, en el códice de Besançon los animales más representados tienen en común ser símbolos de la penitencia y la castidad, aspectos que están relacionados con el contenido de las glosas, como veremos más adelante.

Sobre los aspectos de la vida profana, en esta marginalia se distinguen dos grupos de imágenes: por un lado la representación de los trabajos de los meses, y por otro,

30 SEBASTIÁN LÓPEZ, Santiago (1986), op. cit., pp. 34-35.

31 RANDALL, Lilian M. C. (1966), op. cit., pp. 217-218.

32 SEBASTIÁN LÓPEZ, Santiago (1986), op. cit., p. 127.

33 Ibid., p. 110. 


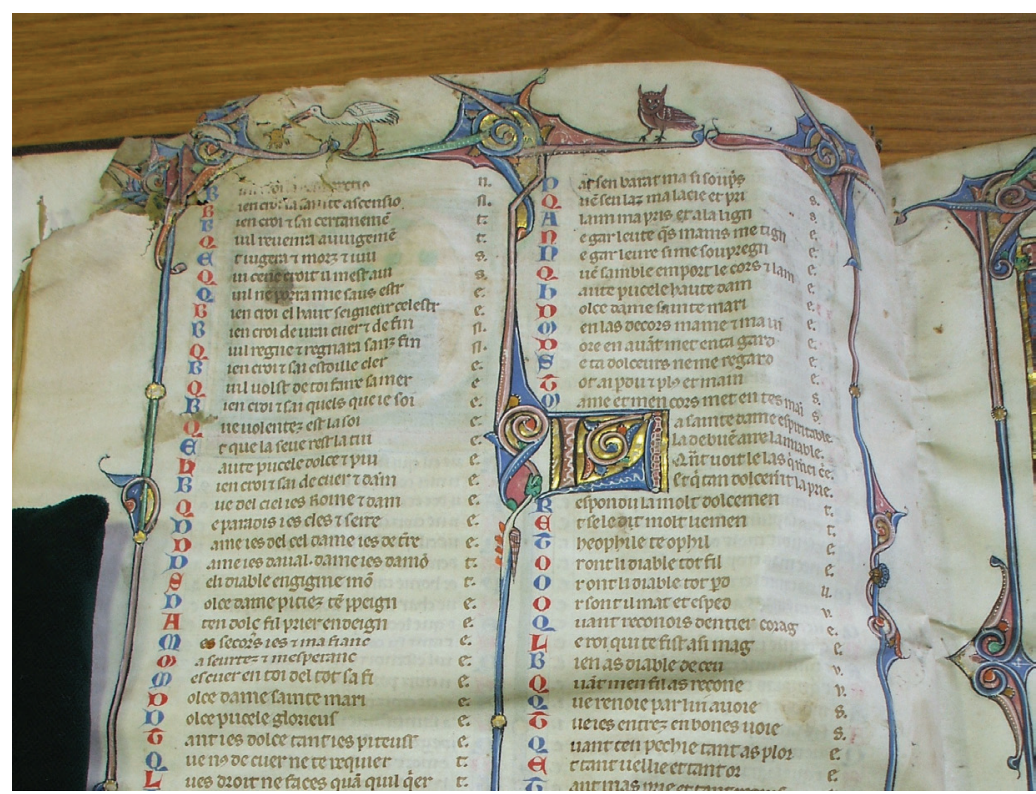

Fig. 3. Cigüeña y búho. Besançon, MS 551, f. 13v, margen superior.

las escenas de caza y torneos de justa. Acerca de los primeros, se suceden en los márgenes superiores desde el f. 20v al f. 23r (fig. 4), a razón de dos meses por folio. A pesar de que su iconografía corresponde a la tradición de los calendarios a partir del siglo XII ${ }^{34}$, a Perrine Mane le llama la atención su disposición dentro de un libro devocional como Les Miracles de Nostre Dame ${ }^{35}$. Los meses de año junto con las numerosas escenas de caza y justa, hablan de la vida profana ligada a las clases altas del poder $^{36}$. Sobre este ejemplar, Patrick Boucheron aclara que algunas de ellas como la del margen inferior del f. 13v (fig. 5), la caza de un oso junto a una escena de cetrería, no solo hacen alusión a la aristocracia sino también a los conceptos de dominación del hombre hacia la mujer ${ }^{37}$. La fuerte presencia de este tipo de escenas suele ser indicativo de un propietario laico. Michael Camille recopila un extenso repertorio que denomina imágenes de la corte, desde luchas cuerpo a cuerpo, torneos de justa e

34 Sobre la iconografía de los meses del año vid. CASTIÑEIRAS GONZALEZ, Manuel, La Iconografía de los meses del años en el Arte Medieval Hispano (siglos XI- XIV), Universidad de Santiago de Compostela, 1993; Idem, El Calendario Medieval Hispano: textos e imágenes (siglos X-XIV), Junta de Castilla y León, 1996; Idem, "El Labora: los trabajos y los días en la iconografía románica", en GARCÍA CORTAZAR, José Antonio (coord.), Vida y muerte en el monasterio románico, 2004, pp. 63-84; Idem, "Trabajo, descanso y refrigerio estival: un topos griego en el calendario medieval hispano", en Troianalexandrina, n 2, 2002, pp. 75-96.

35 MANE, Pierre, "Les travaux et les jours", en DALARUN, Jacques (2002), op. cit., pp. 139-157.

36 ALEXANDER, Jonathan, "Labeur and Paresse: Ideological Representations of Medieval Peasant Labor”, en The Art Bulletin, vol. 72, n 3, 1990, pp. 436-452.

37 BOUCHERON, Patrick, "Signes et Formes de Pouvoir", en DALARUN, Jacques (2002), op. cit., pp. 173-205. 


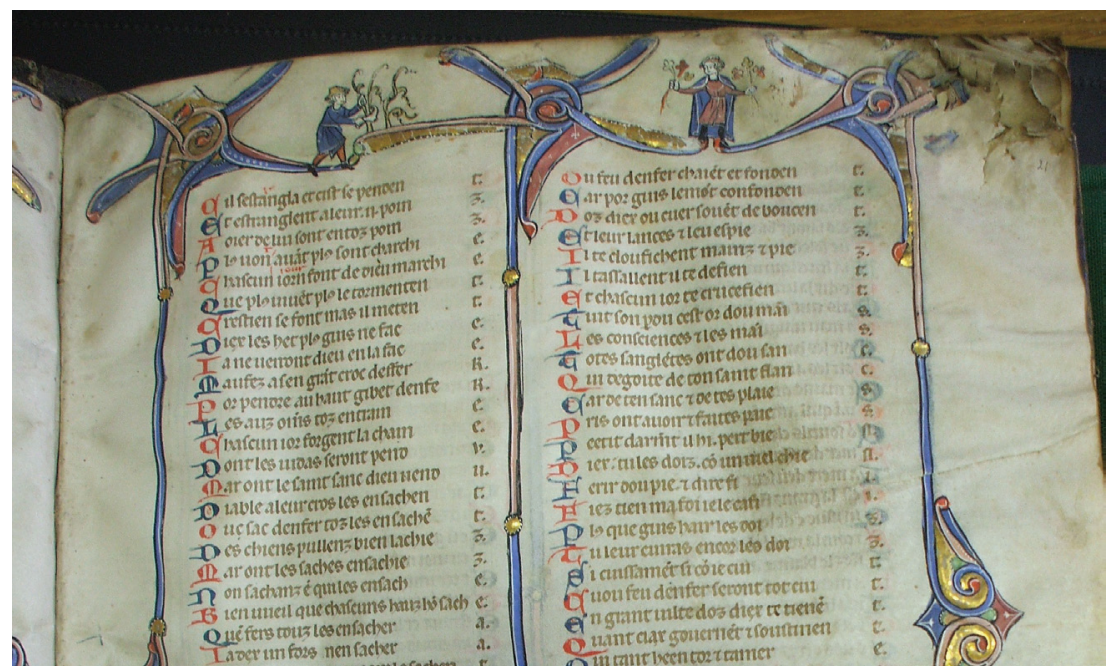

Fig. 4. Meses de marzo y abril. Besançon, MS 551, f. 21r, margen inferior.

incluso escenas de los ciclos artúricos, como una muestra de estatus social aristocrático $^{38}$. Jean Claude Schmitt señala lo mismo, pero alega que más que una ostentación puede ser solamente una alusión a la contemplación de la vida profana ${ }^{39}$, argumento que también apoya Jean Wirth ${ }^{40}$.

Por último señalaremos dos imágenes enfrentadas en el margen inferior del folio 13r (fig. 6). En el lado izquierdo vemos la castración de un animal, y en el otro, la caza del unicornio ${ }^{41}$. La segunda puede estar relacionada con la Encarnación; el unicornio solo puede ser cazado en presencia de una doncella virgen de igual forma que Cristo fue concebido de forma pura en el vientre de María:

"Envían a su encuentro a una pura doncella revestida con una túnica. Y el unicornio salta a su regazo, ella lo amansa, y él la sigue; así lo conduce al palacio del rey. Vemos así que el unicornio es la figura de nuestro Salvador, el cuerno de salvación alzado para nosotros. El tuvo que hacerse carne y morar en el cuerpo de la verdadera Virgen María ${ }^{42 "}$.

Pero debido al requisito que debe tener la mujer usada en su captura también es un símbolo de la pureza, atributo de la Virgen María o de otras vírgenes mártires como

\footnotetext{
38 CAMILLE, Michael (1992), op. cit., pp. 105-106.

39 SCHMITT, Jean-Claude, "L'Univers des Marges”, en DALARUN, Jacques (2002), op. cit., pp. 329361.

40 WIRTH, Jean (2008), op. cit., pp. 195-196.

41 RANDALL, Lilian M. C. (1966), op. cit., pp. 221, CXXXIX.

42 MALAXECHEVERRÍA, Ignacio (2008), op. cit., pp. 194-195,
} 


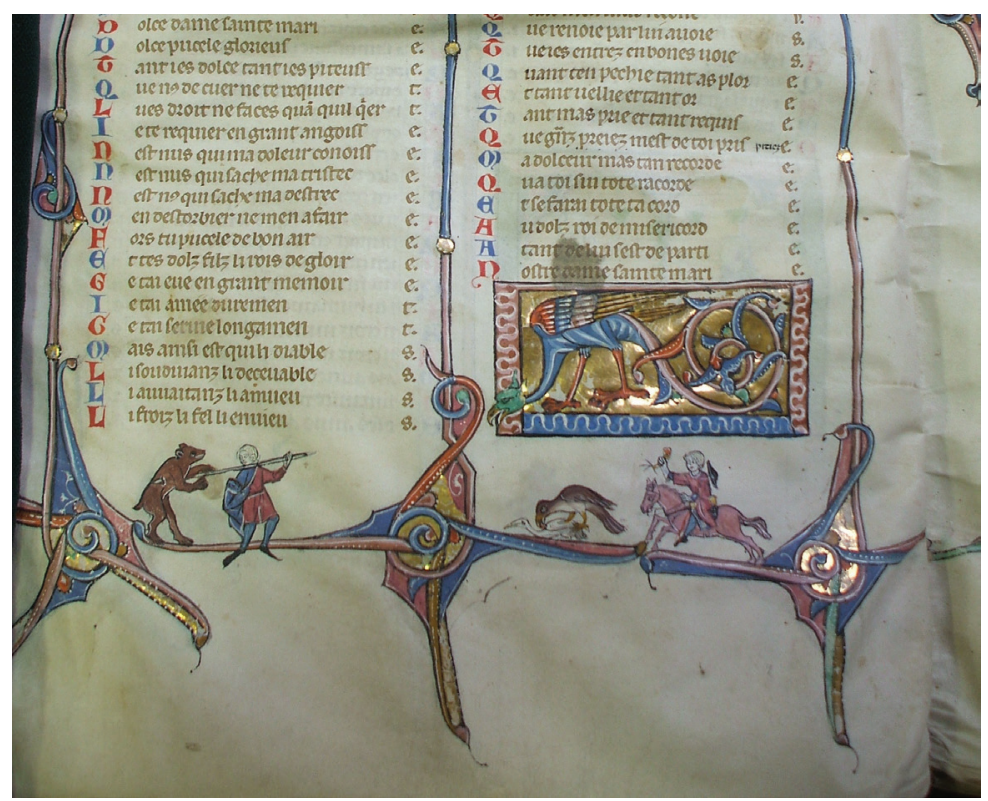

Fig. 5. Caza de un oso y escena de cetreríaa. Besançon, MS 551, f. 13v, margen inferior.

Santa Justina ${ }^{43}$. Oponiéndose a la dama y el unicornio, tenemos un joven que persigue con un perro a un animal cuadrúpedo que acaba de ser castrado. Los genitales eran empleados para el tratamiento de la impotencia masculina, como era el caso del llamado satirión, o los testículos de ciervos, liebres o zorros ${ }^{44}$. Pero también puede ser el ejemplo del castor ${ }^{45}$ :

"Es un animal que tiene un miembro virtuoso. Y cuando es apresado por cazadores, y ve que aquellos lo atrapan con los perros, y conoce la razón por la cual es cazado, se coge los genitales, y con los dientes se los arranca y los echa a tierra (...) este castor nos enseña cómo nos debemos guardar del demonio que nos persigue noche y día ${ }^{46}$ ".

Estas dos escenas, que conjuntamente hablan de la castidad, se complementan con el búho y la cigüeña del margen superior, señalando con más claridad la necesidad de huir de los pecados de la carne y sus tentaciones. Por lo tanto, teniendo en cuenta el

43 Vid. COMEZ RAMOS, Rafael, Imagen y Símbolo en la Edad Media Andaluza, Sevilla, Universidad de Sevilla, 1990, pp. 57-71; D’ASTORG, Bertrand, Le Mythe de la Dame à la Licorne, Paris, Seuil, 1963.

44 MORAL DE CALATRAVA, Paloma, "Frígidos y maleficiados. Las mujeres y los remedios contra la impotencia", en Asclepio. Revista de Historia de la Medicina y la Ciencia, vol. LXIV, 2012, pp. 353-372; RIDER, Catherine, Magic and Impotence in the Middle Ages, Oxford University Press, 2008, pp. 172-176; HERPER, April, "The food of love: Illicit feasting, food imagery and adultery in Old French Literature", en HERPER, April y PROCTOR, Caroline (eds.), Medieval Sexuality, New York, Routledge, 2008, pp. 81-98.

45 RANDALL, Lilian M. C. (1966), op. cit., pp. 69, XVII (79).

46 SEBASTIÁN LÓPEZ, Santiago (1986), op. cit., pp. 38-39. 


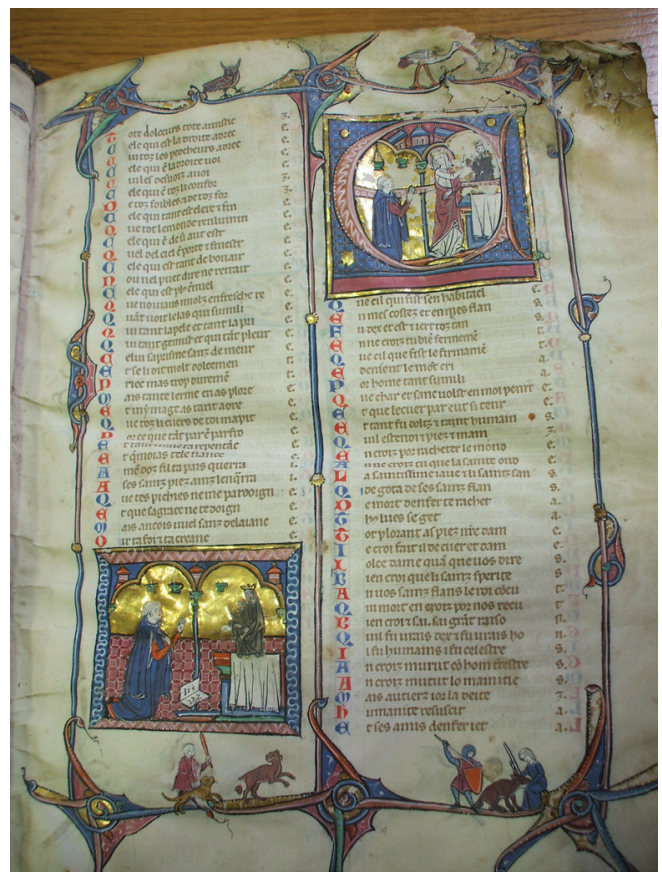

Fig. 6. Cigüeña y búho (margen superior). Caza del unicornio y la castración del castor (margen inferior). Besançon, MS 551, f. 13r.

bestiario comentando anteriormente, y fuera de las escenas de la vida profana, vemos un discurso moral centrado en la penitencia y la castidad, dichas virtudes cobran más sentido cuando se enlazan con el contenido de las glosas, donde tienen un destacado protagonismo.

\section{Discipulus sapiens est gloria summa magistri: la educación de las niñas en el siglo XIII}

Además del repertorio visual de la marginalia, quedaría otro elemento por examinar detenidamente, las anotaciones escritas. Si las primeras apuntan a un encargo laico, las segundas nos pueden indicar el tipo de propietario, concretamente un individuo joven que todavía pudiera estar en periodo de formación y educación. Estas citas se encuentran en los cuadernos segundo, cuarto y último. Al examinar su localización dentro de la página, vemos que se sitúan fuera del esquema del pautado en ambos márgenes, derecho y/o izquierdo. Es interesante señalar que estos pequeños textos estaban proyectados de antemano, puesto que hay algún caso en que el ilustrador ha tenido que modificar su trabajo; en el folio $179 \mathrm{v}$ la glosa ha invadido el espacio del marco, cuyo dibujo tuvo que ser interrumpido. La idea de que los escribas intervinieron antes también se refuerza cuando observamos las características paleográficas, 
tanto las anotaciones como el texto de Gautier están realizados por la misma mano. Así, encontramos un primer grupo distribuido desde el folio 8 al 25, correspondientes al milagro de Teófilo ${ }^{47}$ y parte de la historia de San Ildefonso ${ }^{48}$, y un segundo, del 172 al 179, en la oración que cierra la obra, De la misere d'omme et de fame et de la doutance qu'on doit avoir de morir ${ }^{49}$. La distribución se hace por temas, no habiendo más de uno por margen, a lo sumo dos. Los escribas toman fragmentos de diferentes obras de Padres de la Iglesia, siendo los más citados San Isidoro y San Gregorio, así como de las Sagradas Escrituras, especialmente los Evangelios y Libros Sapienciales, todos ellos del texto latino de la Biblia Vulgata.

Los conceptos más citados en estas glosas son la penitencia, la humildad, la austeridad y la castidad. De la necesidad de confesar los pecados cometidos, advierte el escriba de que todos erramos ${ }^{50}$, y tomando las palabras del evangelio de San Lucas, recuerda que los últimos serán los primeros ${ }^{51}$. Es necesario rendir cuentas al final de la vida, y la confesión se convierte en un elemento indispensable para entrar al Reino de los Cielos ${ }^{52}$, por lo tanto, y a pesar de no figurar como tal, se intuye el derecho al último examen de conciencia y el poder ser perdonado por las faltas cometidas, retomando las palabras de San Gregorio Magno, "Esperar misericordia en la muerte" 53 . El sentimiento de culpa y la necesidad de pedir perdón van ligados a la virtud de la humildad, de la cual encontramos varias alusiones. De todas las cualidades es la que más ensalza el alma humana, puesto que sin ella el resto no son más que polvo ${ }^{54}, \mathrm{y} \sin$ embargo, hay que tener cuidado de no presumir puesto que el humilde no necesita hacerlo $^{55}$ (fig. 7). De esta manera, la humildad se convierte en la piedra angular de este discurso moral, ya que su relación con el resto de enseñanzas es evidente. También

47 Para el texto del milagro de Teófilo vid. GAUTIER DE COINCI (1966), op. cit., vol. 1, pp. 50-176, y su traducción al francés moderno, GARNIER, Annette (ed.), Gautier de Coinci. Le Miracles de Théophile ou comment Théophile vint à la penitence, Paris, Honoré-Champion, 1998.

48 Vid. GAUTIER DE COINCI (1966), op. cit., vol. 2, pp. 5-95; VILAMO- PENTTI, Eva (ed.), De sainte Leocade au tans que sainz Hyldefons estoit arcevesques de Tholete cui Nostre Dame donna l'aube de prelaz, miracle versifié par Gautier de Coinci, Helsinki, Annales Academiae Scientiarum Fennicae, 1950.

49 GAUTIER DE COINCI (1966), op. cit., vol. 4, pp. 439-544; BAUMGARTNER, Emmanuèle y HARFLANCER, Laurence, Seuil de l'œuvre dans le texte médiéval, vol. II, Paris, Presses Sorbonne Nouvelle, 2002 , pp. 219 y ss.; HUNT, Tony, Miraculous Rhymes, Woodbridge, DS Brewer, 2007, pp. 47 y 154-156; LÓPEZ RAMOS, Gloria, "De la misere d'onme et de fame et de la doutance qu'on doit avoir de morir de Gautier de Coinci y su contexto religioso", en ALONSO GARCÍA, Manuel José et al. (eds.), Literatura y Cristiandad. Homenaje al profesor Jesús Montoya Martínez, Granada, Universidad de Granada, 2001, pp. 573-584.

50 Besançon, MS 551, f. 174v, margen derecho: Jacobus, In multis enim offendibus omnes si quis in verbo non offendit hic perfectus est vir (Libro de Jacob 3: 2).

51 Ibid, f. 174r, margen izquierdo: In Evangelio, Erunt novissimi, et novissimi primi (Lucas 13: 30).

$52 \mathrm{Ibid}, \mathrm{f} .173 \mathrm{v}$, margen izquierdo: Nullus desperare debet veniam, eitam si circa finem vitae ad penitenciam conservatur unumquemque enim Deus de suo fine, non vita praeroria indicat (aquí el escriba cita como autor a San Agustín, aunque este fragmento es más acorde a San Isidoro, en su libro de Sentencias 2: 14). Ibid, f. 176v, margen izquierdo: In Evangelio, Penitentiam agite. Apropin quabit enim regnum celorum (Mateo 3: 2).

53 Ibid, f. 176v, margen izquierdo: Gregorius, Satis alienus a fide est, qui ad agendam penitentiam tempora senectutis expectat. Metuendum est ne, dum sperat mosericordiam incidat in mortem.

54 Ibid, f. 176v, margen derecho: Gregorius, Qui enim sine humilitate virtudes congregat, in ventum pulverem portsat.

55 Ibid, f. 17v, margen izquierdo: Isidorus, elatio exc elsos deiecit, arrogantia sublimes humiliant. A pesar de que el escriba cita como autor a San Isidoro, este pasaje concreto corresponde al pasaje de Isaías 64, 2. 


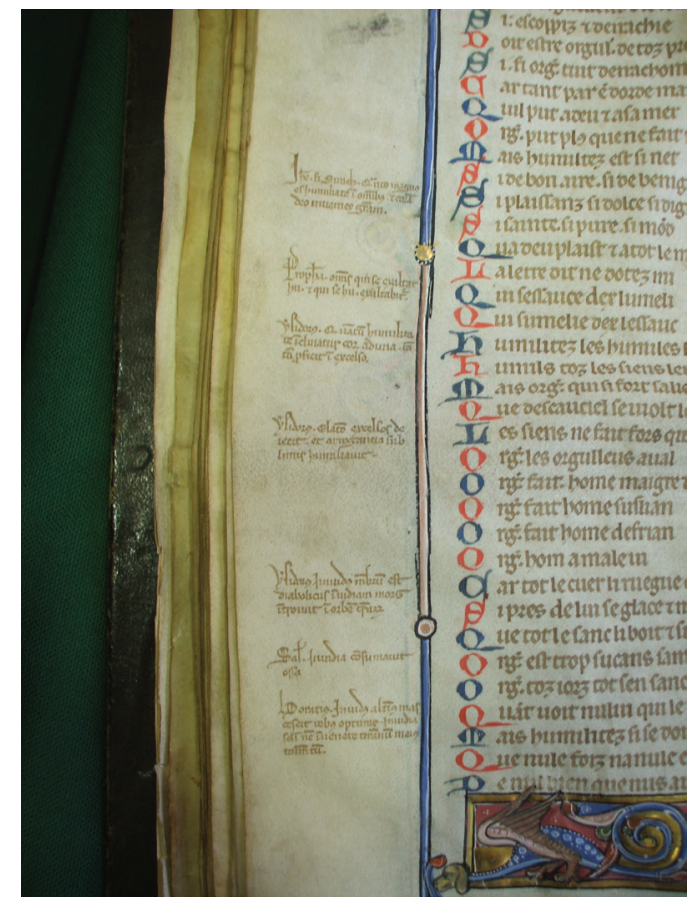

Fig. 7. Glosas latinas. Besançon 551, f. 17r, margen izquierdo.

hay alusiones a la limosna como forma de penitencia ${ }^{56}$, y como expresión de renuncia a los bienes materiales, porque solo los que se desprenden de lo mundano serán salvados $^{57}$. Por último, vuelve a aparecer la virtud de la castidad, enunciada como rechazo al ímpetu y libido de la carne ${ }^{58}$, a los que hay que responder con la renuncia y la huída (fig. 8). El modelo casto por excelencia es la Virgen María de la encontramos dos citas en alusión a su virginidad y pureza ${ }^{59}$. Aunque las anotaciones no siguen un discurso enlazado, sí se puede recomponer un modelo moral basado en estas cuatro cualidades. Dicho ideal se resume de forma explícita en la anotación del margen izquierdo del folio 173v, que aunque el escriba la atribuye a San Anselmo, pertenece a Gregorio Magno: "Effusione sanguinis tua sunt martirii genera. Abstinentia in

$56 \mathrm{Ibid}, \mathrm{f} .172 \mathrm{v}$, margen izquierdo: Daniel, peccata tua elemorfinis redime.

57 Ibid, f. 172v, margen izquierdo: In Evangelio, facilus est camelum per foramen acus transiic quam divitem icrare in regnum celorum. También en el mismo folio, pero en el margen derecho: In Evangelio: date elemosinan et ecce omnia munda sunt vobis. Bendite qui posee et date elemosina.

58 Ibid, f. 174r, margen derecho: Fugitte Fornicationem. Augus, Contra libidinis appetitum et impetum apprendite fugam. Sunt optinere victoria.

59 Ibid, f. 179v, margen izquierdo: Ambrosius, Alvus tumescit virginis claustra pudoris permanet, intra tui uteri claustra qui gubernat omnia; en el mismo folio, en el margen derecho: sancta et inmaculata virginitas quibus te laudibus efferant nescio, qui quen caelo capere non poterant tua gremio contulista. 


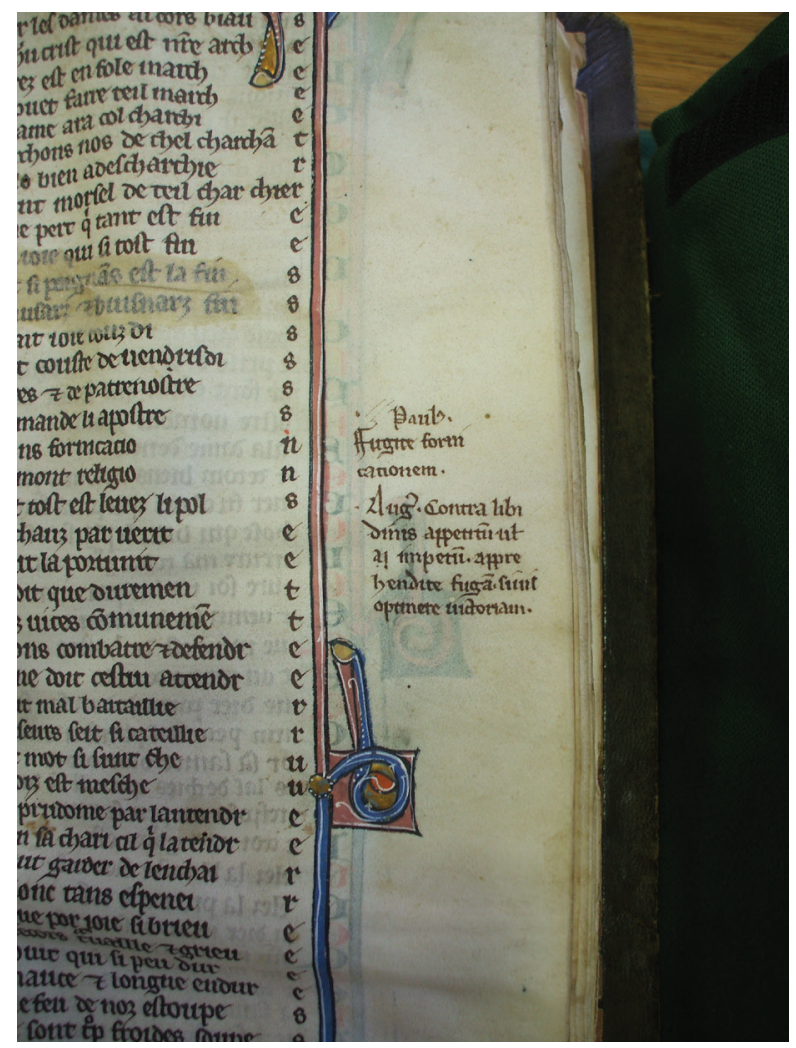

Fig. 8. Glosas latinas. Besançon 551, f. 174r, margen derecho.

divitis, in pauperare largitas, in iuventu castitas". Este fragmento corresponde al denominado martirio blanco, es más liviano, y que cualquier laico puede practicar ${ }^{60}$. ¿Cuál es el sentido de estas glosas? Una primera explicación se encuentra en la cita de Pedro Abelardo, situada en el margen izquierdo del folio 23r, "La mayor gloria del maestro en la sabiduría del alumno" ${ }^{1}$. La intención del encargo va dirigida a que su destinatario saque el mejor provecho del mismo, y que ponga en práctica los consejos que se le dedican como lector. Teniendo en cuenta cuáles son las virtudes más desarrolladas se puede pensar que el contenido va dirigido más bien a una niña que a un niño. En el siglo XIII empiezan a proliferar los tratados dirigidos a mujeres ${ }^{62}$, especialmente a aquellas de clase alta, ya que eran las únicas que podían tener acceso a un ejemplar de estas características, y más si eran ilustrados como el manuscrito

\footnotetext{
60 GREGORIO MAGNO, Homilias sobre los Evangelios, Barcelona, Rialp, 2002, pp. 51 y ss.

61 Besançon, MS 551, f. 23r, margen izquierdo: Petrus Abelardus, discipulus sapiens est gloria summa magistri, laus est illius utilitas.

62 BECEIRO PITA, Isabel, Libros, lectores y biblioteca en la España Medieval, Murcia, Nausícäa, 2007, pp. 560 y ss.; WADE LABARGE, Margaret, La Mujer en la Edad Media, Madrid, Nerea, 1998, pp. 61-62.
} 
de Besançon. La educación femenina se fundamentaba en enseñanzas morales que la convertirían en una perfecta mujer cristiana. La humildad y la castidad son citadas recurrentemente en diferentes textos franceses del momento, como los de Robert de Blois, Vicente de Beauvais, y Phillipe de Novaire, pero también en documentos regios, siendo un buen ejemplo las cartas del rey San Luis a sus hijas, un pequeño escrito dirigido a la reina Blanca de Castilla, e incluso en el ámbito castellano, Alfonso $\mathrm{X}$ en las Siete Partidas hace algunas referencias que siguen estas directrices.

Robert de Blois escribe su poema titulado Le Chastoiement des Dames entre 1230 y $1260^{63}$. A pesar de enumerar una serie de buenas conductas en el ámbito social, la idea central de su discurso es la contención; la misma austeridad y humildad en el vestido o el adorno es la que se tiene que exigir con su cuerpo, que solo puede ser visto y tocado por el marido ${ }^{64}$. Debe ser piadosa con los pobres, cumplir con los rezos y servicios divinos ${ }^{65}$. Con un carácter moral más fuerte son los capítulos dedicados a las mujeres en el tratado De Eruditione Filliorum Nobilium de Vicente de Beauvais ${ }^{66}$, encargado por la reina Margarita de Provenza ${ }^{67}$, esposa de San Luis. Aunque la parte dedicada a la educación femenina es muy reducida, solo los seis últimos capítulos, el dominico comienza con la siguiente reflexión para los padres, “¿Si tienes hijos? Entrénalos y cuida de ellos durante su infancia, ¿Si tienes hijas? Guarda sus cuerpos y no ostentes de ellas" ${ }^{\prime 68}$. Impone una educación moral y rígida que debe ensalzar la humildad, austeridad y castidad como bases para la conducta de la joven ${ }^{69}$. En el apartado sobre la literatura, recomienda que las niñas sepan latín para poder leer las enseñanzas de los Santos Padres, en concreto la epístola Ad Laetam de institutione filiae de San Jerónimo ${ }^{70}$. De esta forma, la lectura no constituye una vía hacia el saber, sino hacia el deber, puesto que solo el fin moral justificaba que una mujer leyera

63 HOWARD FOX, John, Robert de Blois, son auvre didactique et narrative. Étude linguistique et littéraire suivie d'une édition critique avec commentaire et glossaire de l' "Enseignement des princes» et du «Chastoiement des dames», Paris, Nizet, 1950.

64 HENTSCH, Alice Adèle, De la littérature didactique du Moyen Âge s'adressant spécialement aux femmes, Paris, Cahors, 1903, p. 76.

65 Ibid, p. 78.

66 ADEVA MARTÍN, Ildefonso y VERGARA CIORDIA, Javier, Vicente de Beauvais. Tratado sobre la formación de los hijos de los nobles, Madrid, Universidad Nacional de Educación a distancia, 2011.

67 Margarita de Provenza (1221-1295) encarga este tratado a Vicente de Beauvais en la década de 1250. Fue una reina muy involucrada en la educación de sus hijos debido a las ausencias de su marido, el rey San Luis, por causa de las cruzadas. Vid. BOUTARIC, M. Edgard, "Marguerite de Provence. Son caractère, son rôle politique", en Revue de questions Historiques, vol. 3, 1867, pp. 417-459; GIL, Christiane, Marguerite de Provence. Épouse de Saint- Louis, mère de Philippe III, Paris, Pygmalion, 2006; SIVÉRY, Gérard, Marguerite de Provence: une reine au temps des cathédrales, Paris, Fayard, 1987.

68 "Filii tibi sunt? Erudi illos et curna illos a puerica eorum. Filie tibi sunt? Serva corpus earum et non ostendas hyllarem faciem tuam ad illas", vid. ADEVA, Ildefonso y VERGARA, Javier (2011), op. cit., pp. 644-645.

69 BARTON TOBIN, Rosemary, "Vincent of Beauvais on the Education of Women", en Journal of the History of Ideas, vol. 35, $\mathrm{n}^{\circ}$ 3, 1974, pp. 485-489; GABRIEL, Astrik 1., The Education Ideas of Vincent of Beauvais, Notre Dame: The Mediaeval Institute, University of Notre Dame, 1956; L'HERMITE LECLERCQ, Paulette, "L'image de la femme dans le De Euriditione Filiorum Nobilium de Vincent de Beauvais", en ROUCHE, Miche (dir.), Mariage et Sexualité au Moyen Âge. Accord ou crise?, Paris, Presses de 1'Université de Paris - Sorbonne, 2000, pp. 243-261.

70 HENTSCH, Alice Adèle (1903), op. cit., pp. 27-30. 
latín. También escribe un apartado sobre el ornamento superficial, donde recomienda a los padres no engalanar a sus hijas en exceso, ya que su belleza no debe ser expuesta de manera tan impúdica, porque lo único que se consigue es encender la libido y las pasiones de la carne ${ }^{71}$. Esta precaución sobre el cuerpo va ligada a la gran virtud de la mujer cristiana, que según este autor es la castidad. Se debe enseñar a la mujer a templar las tentaciones de la carne, puesto que es más vulnerable y va implícito en su naturaleza femenina ${ }^{72}$. Por ello, declara al padre responsable de custodiar a su hija para evitar que caiga en la lujuria, recomendándole el castigo físico si hiciera falta ${ }^{73}$. El último tratado es el de Phillipe de Novaire, Des quatre tens d'aage d'ome, escrito en prosa antes de $1270^{74}$. Al igual que los anteriores, impone a la mujer el ser sumisa ante Dios y su marido. Aunque aclara que no tiene por qué saber leer y escribir, sí le recomienda ser caritativa, humilde y casta, tomando como modelo a la misma Virgen María $^{75}$. Su vida debe ser sencilla, regida por la moderación, la moral y el amor a Dios.

Estas recopilaciones no difieren mucho de los pocos documentos que encontramos en el contexto regio. En el texto anónimo Le mirroir de l'Ame ${ }^{76}$, dirigido seguramente a la reina Blanca de Castilla ${ }^{77}$, el autor desarrolla las razones para practicar las virtudes cristianas exclusivas para las mujeres; la felicidad celeste, las penalidades eternas, el temor a la muerte, la lucha contra los apetitos del cuerpo y los peligros de la vida mundana. Impregnado de un gran misticismo, volvemos a encontrar la humildad y la castidad como atributos especialmente femeninos. Una visión más íntima de estas enseñanzas morales, son las de las cartas escritas por San Luis a sus hijas, Blanca e Isabel ${ }^{78}$. El rey recurre al afecto que siente por ellas para aconsejarles que vayan a la iglesia y cumplan con los servicios devocionales, que se rodeen de

71 ADEVA MARTÍN, Ildefonso y VERGARA CIORDA, Javier (2011), op. cit., pp. 666-667.

72 BARTON TOBIN, Rosemary (1974), op. cit., p. 488.

73 Ibid, p. 486 cfr. ADEVA MARTÍN, Ildefonso y VERGARA CIORDA, Javier (2011), op. cit., pp. 648653.

74 DE FREVILLE, Marcel (ed.), Des quatre âges de l'homme: traité de moral de Philippe de Novare, Paris, Didot, 1888.

75 HENTSCH, Alice Adèle (1903), op. cit., pp. 83-86.

76 Ibid, pp. 74-75.

77 Blanca de Castilla (1188-1252), madre del rey San Luis, además de su carácter fuertemente devocional y consejera de su hijo, destacó por el encargo de importantes manuscritos, entre ellos las Biblias Moralizadas, donde dejó su impronta personal. Vid. SIVÉRY, Gérard, Blanche de Castille, Paris, Fayard, 1990. Sobre su actividad como patrona, SCHOWALTER, Kathleen, Capetian Women and their books: Art, Idelogy, and Dinastic continuity in Medieval France, Tesis Doctoral, Johns Hopkins University, Baltimore, 2005, y los dos capítulos, SHADIS, Miriam, "Blanche of Castille and Facinger's Medieval Queenship" (pp. 3- 48), y CHAPMAN HAMILTON, Tracy, "Queenship and Kingship in the French Bible Moralisée: the example of Blanche of Castille and Viena ÖNB 2554" (pp. 177- 208), en NOLAN, Kathleen (ed.), Capetian Woman, New York, Palgrave MacMillan, 2003.

78 Sobre los modelos espirituales de San Luis y su corte, vid. JORDAN, William Chester, "Isabelle of France and Religious Devotion at the Court of Louis IX", en NOLAN, Kathleen (2003), op. cit., pp. 209-223; Idem, "Louis IX: preaching to Franciscan and Dominican Brothers and Nuns", en CUSATO, Michael F. y GELTNER, Guy (eds.), Defenders and Critics of Franciscans Life: Essays in Honour of John V. Fleming, Leiden, Brill, 2009, pp. 219- 235, LORDAN, Kevin L., A mirror for a king: Guibert de Tournai's Eruditio Regum et Principum and Louis IX of France, Boulder, University of Colorado, 2012, especialmente las páginas dedicadas a Isabel de Francia, hermana de San Luis (pp. 28- 37). 
buenas compañías, que no tengan demasiados vestidos y joyas y que ese dinero lo destinen a obras de caridad, deben ser caritativas con los desfavorecidos y obedecer a sus maridos, siempre que no suponga contradecir la palabra de Dios ${ }^{79}$. Aunque son los consejos de un padre hechos en la intimidad, existe una relación directa con los tratados anteriormente vistos, no más lejos, el propio Vicente de Beauvais era uno de los intelectuales que trabajó para el rey San Luis. La corte de Alfonso X poseía un ambiente muy similar al visto en su homóloga francesa. Él mismo recomienda para las niñas la lectura de salterios, mesura en la comida y el vestido ${ }^{80}$. En Las Siete Partidas $^{81}$ se recoge la importancia de que sepan leer y escribir, aunque con una finalidad moral. Mientras los modelos masculinos son los ejemplos del guerrero y el sabio, Alejandro Magno y Salomón, el de las mujeres debían ser la Virgen y las santas ${ }^{82}$. En el siglo XIII la moral de las órdenes mendicantes tuvo una especial repercusión en los modelos de conducta y educación tanto de niños como niñas. En el caso femenino, como hemos visto, dicho programa se resumía en tres virtudes, humildad, caridad y castidad, tomando como ejemplo a la Virgen, lo cual debía condicionar su rol como esposas fieles y sumisas. El acceso a la lectura no estaba prohibido, pero el único fin era la instrucción moral.

Por lo tanto podemos comprobar como las características codicológicas y el contenido de los márgenes, inducen a pensar que el receptor del códice de Besançon pudiera ser una niña. En primer lugar, la presencia de un texto principal en francés con las anotaciones en latín no desentona con la costumbre educativa, la niña podía leer con la única intención de comprender las enseñanzas de las Sagradas Escrituras y Santos Padres, como ocurre en este caso ${ }^{83}$. En segundo, Les Miracles de Nostre Dame es una obra más devocional que hagiográfica, como expresa su autor en el prólogo del primer libro ${ }^{84}$, propósito principal que debía tener la lectura para las mujeres. Es más, se sabe que dos códices conservados en la Biblioteca Nacional de Francia, MS 24541 y MS 22928, se hicieron para mujeres de la familia real francesa ${ }^{85}$. Y en último lugar, el discurso que encontramos en los márgenes se centra en una serie de virtudes especialmente femeninas. La humildad, la caridad y, especialmente, la castidad se incluían en los discursos dedicados a las mujeres, no a los hombres. De hecho, el único

79 HENTSCH, Alice Adèle (1903), op. cit., pp. 80-83.

80 BECEIRO PITA, Isabel (2007), op. cit., p. 131 y ss.

81 ALFONSO X EL SABIO, Las Siete Partidas, Madrid, Lex Nova, 1989 (ed. facs. 1491). Sobre las educación de las mujeres, vid. Partida II, título VII, ley XI.

82 BECEIRO PITA, Isabel (2007), op. cit., p. 162.

83 Sobre el uso de estas glosas en los manuscritos de Gautier de Coinci, Keith Busby aclara que su función era doble, por un lado la instrucción y por otro, la demostración de un cierto estatus intelectual, BUSBY, Keith, Codex and Context. Reading Old French Narrative in Manuscript, vol. 1, Amsterdam-New York, Rodopi, 2002, pp. 223-224.

84 "Quiero trasladar en rima y metro los milagros que encontré en latín, para que aquellos y aquellas que esta lengua no entiendan, sepan que hacen bien en dedicarse a su servicio": MONTOYA MARTÍNEZ, Jesús (1979-1980), op. cit., p. 43.

85 Sobre el MS 22928 de la Biblioteca Nacional de Francia, Alison Stones apunta que pudo pertenecer a la hija de San Luis o alguien de su entorno, por figurar en la ilustración del milagro de San Ildefonso, los escudos de Castilla y Francia: STONES, Alison (2006), op. cit., p. 90. Acerca del conocido como Manuscrito de Soissons (BnF, n. acq. fr. 24541), se sabe que perteneció a la reina Jeanne d'Evreux (1307-1370), vid. RUSSAKOFF, Anna (2006), op. cit. 
modelo que aparece en el códice de Besançon es la Virgen María, que como hemos visto aparece en los textos de Vicente de Beauvais y Philippe de Novaire. En algunos casos, estas citas se ven complementadas con las imágenes de la marginalia. Recordemos el águila y león, símbolos de la penitencia y la purificación del alma, la cigüeña, representante de la castidad, o la oposición entre la castración del castor y la caza del unicornio, que hacen alusión a la virginidad y abstinencia carnal. Aquellas imágenes que pueden tener un uso más allá de la ornamentación coinciden con las citas en los mismos conceptos e ideas. En este caso, los márgenes se han convertido en el espacio para un discurso orientado a la vida profana, destinado a mostrar cuáles son las virtudes de la mujer cristiana, las cuales tendrá que aplicar en su futuro día a día. 